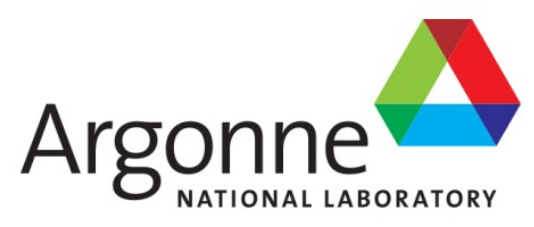

ANL/CSE-13/3

\title{
Mechanical Stability Study
}

Chemical Science and Engineering Division 


\begin{abstract}
About Argonne National Laboratory
Argonne is a U.S. Department of Energy laboratory managed by UChicago Argonne, LLC under contract DE-AC02-06CH11357. The Laboratory's main facility is outside Chicago, at 9700 South Cass Avenue, Argonne, Illinois 60439. For information about Argonne and its pioneering science and technology programs, see www.anl.gov.
\end{abstract}

\title{
Availability of This Report
}

This report is available, at no cost, at http://www.osti.gov/bridge. It is also available on paper to the U.S. Department of Energy and its contractors, for a processing fee, from:

U.S. Department of Energy

Office of Scientific and Technical Information

P.O. Box 62

Oak Ridge, TN 37831-0062

phone (865) 576-8401

fax (865) 576-5728

reports@adonis.osti.gov

\section{Disclaimer}

This report was prepared as an account of work sponsored by an agency of the United States Government. Neither the United States Government nor any agency thereof, nor UChicago Argonne, LLC, nor any of their employees or officers, makes any warranty, express or implied, or assumes any legal liability or responsibility for the accuracy, completeness, or usefulness of any information, apparatus, product, or process disclosed, or represents that its use would not infringe privately owned rights. Reference herein to any specific commercial product, process, or service by trade name, trademark, manufacturer, or otherwise, does not necessarily constitute or imply its endorsement, recommendation, or favoring by the United States Government or any agency thereof. The views and opinions of document authors expressed herein do not necessarily state or reflect those of the United States Government or any agency thereof, Argonne National Laboratory, or UChicago Argonne, LLC. 


\section{Mechanical Stability Study}

by

Elizabeth O. Krahn' ${ }^{1}$, Andrew S. Hebden', George F. Vandegrift', Pei-Lun Chung², and Nien-Hwa Linda Wang ${ }^{2}$

${ }^{1}$ Chemical Science and Engineering Division, Argonne National Laboratory

${ }^{2}$ BioSeparations Laboratory, School of Engineering, Purdue University

prepared for

U.S. Department of Energy, National Nuclear Security Administration, Office of Defense Nuclear Nonproliferation

July 2010 



\section{CONTENTS}

INTRODUCTION

2 BACKGROUND

3 SUMMARY

4 CONCLUSIONS

FUTURE WORK

6 REFERENCES .

APPENDIX A: Viscosity of a 145 g-U/L Uranyl Nitrate Solution .................................... 7

APPENDIX B: Pressure Drop Calculation by Using Ergun’s Equation ............................. 8

APPENDIX C: Scaled-Down MIPS Column Mechanical Stability Study

\section{FIGURES}

C-1 Mechanical Stability Study Setup ............................................................ 9

C-2 S80 Mechanical Stability Study, 145 g-U/L Uranyl Nitrate Solution ........................ 11

C-3 T5M Mechanical Stability Study, 145 g-U/L Uranyl Nitrate Solution ....................... 12

C-4 T52 Mechanical Stability Study, 145 g-U/L Uranyl Nitrate Solution .......................... 13

\section{TABLES}

$1 \quad$ Scaled-Down MIPS Columns ..................................................................... 2

2 Column Dimensions for Mechanical Stability Study ........................................... 3

B-1 Calculated $\Delta \mathrm{P}$ for the Mechanical Stability Study Columns .................................. 8

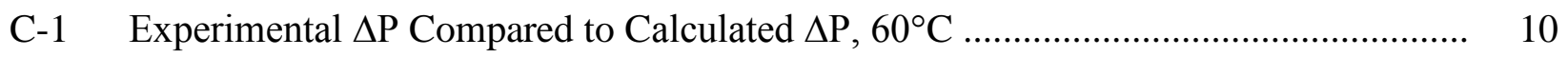

C-2 Experimental $\Delta \mathrm{P}$ Versus Calculated $\Delta \mathrm{P}$ with a $145 \mathrm{~g}-\mathrm{U} / \mathrm{L}$ Uranyl Nitrate Solution, $\mathrm{pH} 1$ at $60^{\circ} \mathrm{C}$ 


\section{MECHANICAL STABILITY STUDY}

\section{INTRODUCTION}

Argonne National Laboratory (Argonne), in collaboration with the BioSeparations Laboratory at Purdue University, is helping Babcock and Wilcox Technical Services Group develop the Medical Isotope Production System (MIPS), which will use an aqueous homogenous reactor (AHR) for the domestic production of ${ }^{99} \mathrm{Mo}$. Roughly $200 \mathrm{~L}$ of low enriched uranium (LEU, 19.75\% U-235) as a uranyl nitrate solution will be irradiated and passed through a column, which has been pre-equilibrated with nitric acid, for 2 hours. Column sizes have been predicted for the plant-scale production of ${ }^{99}$ Mo by using Purdue University's Versatile Reaction Separation (VERSE) simulator and experimental data provided by Argonne. In the plant, these columns will undergo multiple loading/washing/stripping cycles to purify ${ }^{99}$ Mo from batches of irradiated LEU solutions. Since the previous report was distributed, the selection of sorbents to be used in the columns has been reduced to three titania-based sorbents.

This report describes the results from mechanical stability studies that were performed to test the pressure drop and sorbent resistance to stress under relevant process conditions. 


\section{BACKGROUND}

Three titania-based sorbents are currently being examined as potential MIPS column candidates: Satchopore-80, a pure titania sorbent (S80, $\mathrm{TiO}_{2}$ ); Termoxid-52 (T52, 25 mol\% SnO 2 and $75 \mathrm{~mol} \% \mathrm{TiO}_{2}$ ); and Termoxid-5M (T5M, $5 \mathrm{~mol} \% \mathrm{ZrO}_{2}$ and $95 \mathrm{~mol} \% \mathrm{TiO}_{2}$ ). Previous reports examined molybdenum uptake by each sorbent through batch contact studies and frontal tests. In addition, multiple criteria for the column design need to be met for the MIPS production scale: (1) $200 \mathrm{~L}$ of fuel solution must be passed through the column in 2 hours; (2) the column length must be greater than the length of the mass transfer zone calculated by using the VERSE code; and (3) a pressure drop $(\Delta \mathrm{P})$ constraint of less than $0.8 \mathrm{~atm}$ needs to be maintained, based on the MIPS design, which will use a vacuum/gravity flow transfer system. The maximum column length, consistent with the $\Delta \mathrm{P}$ constraint of $0.8 \mathrm{~atm}$, was calculated by using Ergun's equation, as previously described (Chung and Wang 2010). For use in these calculations, the viscosity of a $145 \mathrm{~g}-\mathrm{U} / \mathrm{L}$ uranyl nitrate solution $\left(\mathrm{pH}\right.$ of 1 at $60^{\circ} \mathrm{C}$ ) was experimentally determined to be $0.74 \mathrm{cP}$ (see Appendix A).

The experimental set-up for the loading, washing, and stripping of ${ }^{99} \mathrm{Mo}$ in the column is as follows. The ${ }^{99}$ Mo will be loaded onto the column in the upflow direction in 2 hours. Previous data showed that the sorbents have a slight affinity for uranium, so the uranium will be washed from the column by using $0.1 \mathrm{M}$ nitric acid. The column is washed with water immediately before the ${ }^{99} \mathrm{Mo}$ is stripped from the column in the downflow direction by using $1 \mathrm{M}$ ammonium hydroxide. After all of these steps have been performed, there is a final water rinse to prepare the column for storage conditions and future runs. To determine the extent to which these columns can be reused, mechanical stability tests were performed on scaled-down MIPS columns (Table 1).

TABLE 1 Scaled-Down MIPS Columns

\begin{tabular}{|c|c|c|c|c|c|c|c|c|}
\hline \multirow[b]{2}{*}{ Sorbent } & \multirow[b]{2}{*}{$\begin{array}{c}d_{p}, \text { Avg. } \\
(\mu \mathrm{m})\end{array}$} & \multirow[b]{2}{*}{$\mathrm{ID}^{\mathrm{a}}(\mathrm{cm})$} & \multirow[b]{2}{*}{$\begin{array}{r}u_{\text {superficial }} \\
(\mathrm{cm} / \mathrm{min})\end{array}$} & \multirow[b]{2}{*}{$\begin{array}{c}\text { Pressure } \\
\text { Drop } \\
\text { (atm) }\end{array}$} & \multirow[b]{2}{*}{$\begin{array}{c}\text { Flow Rate } \\
\text { (mL/min) }\end{array}$} & \multicolumn{3}{|c|}{ Loading Time $=2$ hours } \\
\hline & & & & & & $\begin{array}{l}\mathrm{L}_{\min } \\
(\mathrm{cm}) \\
\end{array}$ & $\begin{array}{l}\mathrm{CV}_{\text {min }} \\
(\mathrm{mL})\end{array}$ & $\begin{array}{l}\text { Feed } \\
(\mathrm{mL})\end{array}$ \\
\hline \multirow[t]{3}{*}{ T52 } & 300 & 1.5 & 1 & 0.001 & 1.8 & 3 & 5.3 & 212 \\
\hline & & 1.5 & 5 & 0.019 & 8.8 & 10 & 18 & 1060 \\
\hline & & 1.5 & 21 & 0.3 & 37.1 & 37 & 65 & 4453 \\
\hline \multirow[t]{3}{*}{ T5M } & 300 & 1.5 & 1 & 0.001 & 1.8 & 3 & 5.3 & 212 \\
\hline & & 1.5 & 5 & 0.011 & 8.8 & 10 & 18 & 1060 \\
\hline & & 1.5 & 21 & 0.17 & 37.1 & 35 & 62 & 4453 \\
\hline \multirow[t]{5}{*}{ S80 } & 80 & 1.5 & 1 & 0.005 & 1.8 & 1 & 1.8 & 212 \\
\hline & & 1.5 & 5 & 0.06 & 8.8 & 3 & 5 & 1060 \\
\hline & & 1.5 & 9 & 0.13 & 16 & 4 & 7 & 1909 \\
\hline & & 1.5 & 15 & 0.3 & 26.5 & 6 & 11 & 3181 \\
\hline & & 1.5 & 21 & 0.7 & 37.1 & 9 & 16 & 4453 \\
\hline
\end{tabular}

a $\quad$ ID = internal diameter. 


\section{SUMMARY}

Columns for the longest $\mathrm{L}_{\min }$ of each sorbent (Table 2) were packed as previously described (Chung and Wang 2010). They were chosen based on the fact that they have the fastest possible superficial velocity that could be used in the plant-scale design. Tests were performed at a flow rate of $37.1 \mathrm{~mL} / \mathrm{min}$ for water (8 hours), $0.1 \mathrm{M} \mathrm{HNO}_{3}$ (8 hours, 3 times), and $1 \mathrm{M} \mathrm{NH}_{4} \mathrm{OH}$ (1 hour, 3 times). The temperature of the column was equilibrated to $60^{\circ} \mathrm{C}$ while the solution was passed through it. Once equilibrium was

TABLE 2 Column Dimensions for Mechanical Stability Study

\begin{tabular}{ccc}
\hline & & \\
Sorbent & ID (cm) & Length (cm) \\
\hline & & \\
S80 & 1.5 & 12 \\
T52 & 1.5 & 38 \\
T5M & 1.5 & 40 \\
\hline
\end{tabular}
reached, the change in pressure remained constant for the duration of the experiment. The pressure changes were compared to the calculated change by using Ergun's equation (Appendix B). The experimental $\Delta \mathrm{P}$ for the $\mathrm{S} 80$ and T5M column closely matched the calculated value, within experimental error. The experimental $\Delta \mathrm{P}$ for the T52 was initially close to that calculated; after a couple of hours, it became lower than the calculated value but still remained within the experimental error due to the large range of particle sizes in the Termoxid sorbents (Appendix C).

The next tests involved passing a $145 \mathrm{~g}-\mathrm{U} / \mathrm{L}$ uranyl nitrate solution at $\mathrm{pH} 1$ through the columns and monitoring the pressure. When the $\mathrm{S} 80$ and T5M sorbents were used, the pressure drop through the column remained constant and within experimental error throughout the test. In addition, there were no significant pressure increases throughout the runs. In contrast, the T52 column's pressure increased for roughly 15 hours, and then the pressure dropped down to background (Appendix C). 


\section{CONCLUSIONS}

The data obtained during the mechanical stability study suggest that the S80 and T5M sorbent are more stable at the higher flow rates over longer periods of time than is T52. The pressure drop that was measured while the 145 g-U/L uranyl nitrate solution was passed through the S80 and T5M columns did not change significantly over the given time frame, which suggests that these sorbents are better candidates for the plant-scale production. The T52 column did not perform well in the tests with uranyl nitrate because the pressure drop through the column steadily increased throughout the course of the run until it dropped to background. This result suggests that the particles could break down, leading to the formation of channels over time; thus, the T52 column, at this length and velocity, is not an ideal candidate for the plantscale column.

When these data are considered in conjunction with the results previously reported for the Mo 2-hour loading experiments (Ziegler et al. 2010), they indicate that the S80 column performed well in the mechanical stability studies and recovered close to $100 \%$ of the Mo. The T5M columns, while showing mechanical stability, did not recover more than $60 \%$ of the Mo. The longest T52 column did not perform well in the mechanical stability tests or Mo recovery. However, the $1.5 \times 10 \mathrm{~cm}$ (internal diameter or ID $\times$ length) T52 column recovered $96 \%$ of the Mo, so it would be beneficial to investigate if the T52 sorbent would be more stable at a lower velocity. 


\section{FUTURE WORK}

The sorbents that have undergone the mechanical stability test will be used in batch contact studies. The sorbent will be sampled from the inlet, middle, and outlet of the column. These results will be compared to those obtained from using sorbents that have not undergone these stresses to determine whether the extent to which they bind Mo changes throughout the run. The mechanical stability test for the T52 column will be repeated at $21 \mathrm{~cm} / \mathrm{min}$ by using fresh sorbent, and if this pressure increase is still seen, perhaps a velocity of $5 \mathrm{~cm} / \mathrm{min}$ should be investigated. Stripping conditions are currently being optimized, and the data obtained will be used to determine which sorbent is most stable and recovers $100 \%$ of the Mo. 


\section{REFERENCES}

Ziegler, A.J., et al., 2010, unpublished information, Argonne National Laboratory, Argonne, Ill., June 30. 


\section{APPENDIX A:}

\section{VISCOSITY OF A 145 g-U/L URANYL NITRATE SOLUTION}

The viscosity of a solution describes its resistance to flow and is important in determining the $\Delta \mathrm{P}$ across the column packing. The viscosity of a $145 \mathrm{~g}-\mathrm{U} / \mathrm{L}$ uranyl nitrate solution was experimentally determined at $25^{\circ} \mathrm{C}$ (density, $1.19 \mathrm{~g} / \mathrm{mL}$ ) and $60^{\circ} \mathrm{C}$ (density, $1.28 \mathrm{~g} / \mathrm{mL}$ ) using a cross arm viscometer from Technical Glass Products, Inc. The flow time of the solution in the viscometer was measured in triplicate for each temperature. The results for the kinematic

viscosity are $1.14 \mathrm{cS}$ at $25^{\circ} \mathrm{C}$ (dynamic viscosity, $1.36 \mathrm{cP}$ ) and $0.58 \mathrm{cS}$ at $60^{\circ} \mathrm{C}$ (dynamic viscosity, $0.74 \mathrm{cP})$. 


\section{APPENDIX B:}

\section{PRESSURE DROP CALCULATION BY USING ERGUN'S EQUATION}

The Ergun equation can be used to determine the pressure drop of the packing $(\Delta \mathrm{P})$ given the particle size, superficial velocity, interparticle void fraction, and column length:

$$
\Delta P=L \times\left[150 \frac{\left(1-\varepsilon_{b}\right)^{2}}{\varepsilon_{b}{ }^{3}} \frac{\mu u_{s}}{d_{p}{ }^{2}}+1.75 \frac{\left(1-\varepsilon_{b}\right)}{\varepsilon_{b}{ }^{3}} \frac{\rho u_{s}{ }^{2}}{d_{p}}\right]
$$

where $L$ is the column packing length, $\varepsilon_{b}$ is the interparticle void fraction, $\mu$ is the viscosity of the mobile phase, $u_{s}$ is the superficial velocity, $d_{p}$ is the particle diameter, and $\rho$ is the density of the mobile phase. The $\Delta \mathrm{P}$ was calculated for the columns packed for the mechanical stability studies with water and $145 \mathrm{~g}-\mathrm{U} / \mathrm{L}$ uranyl nitrate solution at $60^{\circ} \mathrm{C}$ (Table B-1).

TABLE B-1 Calculated $\Delta P$ for the Mechanical Stability Study Columns

\begin{tabular}{llccccccc}
\hline & & & & & & & \\
& Mobile Phase & $\begin{array}{c}\text { Lengt } \\
\mathrm{h}(\mathrm{cm})\end{array}$ & $\varepsilon_{b}$ & $\begin{array}{c}\text { us } \\
(\mathrm{cm} / \mathrm{min})\end{array}$ & $\begin{array}{c}\mu \\
(\mathrm{cP})\end{array}$ & $\begin{array}{c}d_{p} \\
(\mu \mathrm{m})\end{array}$ & $\begin{array}{c}\rho \\
(\mathrm{g} / \mathrm{mL})\end{array}$ & $\begin{array}{c}\Delta \mathrm{P} \\
(\mathrm{atm})\end{array}$ \\
\hline \multirow{2}{*}{ S80 } & & & & & & & \\
& Water & 12 & 0.33 & 21 & 0.47 & 80 & 0.98 & 0.60 \\
& Uranyl nitrate & 12 & 0.33 & 21 & 0.74 & 80 & 1.28 & 0.91 \\
& & & & & & & & \\
T52 & Water & 38 & 0.30 & 21 & 0.47 & 300 & 0.98 & 0.20 \\
& Uranyl nitrate & 38 & 0.30 & 21 & 0.74 & 300 & 1.28 & 0.30 \\
& & & & & & & & \\
T5M & Water & 40 & 0.34 & 21 & 0.47 & 300 & 0.98 & 0.12 \\
& Uranyl nitrate & 40 & 0.34 & 21 & 0.74 & 300 & 1.28 & 0.20 \\
\hline
\end{tabular}




\section{APPENDIX C:}

\section{SCALED-DOWN MIPS COLUMNS MECHANICAL STABILITY STUDY}

\section{C.1 EXPERIMENTAL SETUP}

The mechanical stability studies with water, $0.1 \mathrm{M}$ $\mathrm{HNO}_{3}$, and $1 \mathrm{M} \mathrm{NH}_{4} \mathrm{OH}$ were performed by using a highpressure peristaltic pump with a flow rate of $37.1 \mathrm{~mL} / \mathrm{min}$ (superficial velocity of $20 \mathrm{~cm} / \mathrm{min}$ ). The column was wrapped in heat tape (T52, T5M) or placed in a water jacketed column (S80) to maintain a temperature of $60^{\circ} \mathrm{C}$ (Figure C-1). The solution was continuously passed through the column as follows: for 8 hours with $\mathrm{H}_{2} \mathrm{O}$; for 8 hours three times with $0.1 \mathrm{M} \mathrm{HNO}_{3}$; and for 1 hour three times with $1 \mathrm{M} \mathrm{NH}_{4} \mathrm{OH}$. The background pressure was measured with a column filled with water at $60^{\circ} \mathrm{C}$ and recorded to determine the pressure drop in the sorbent.

For the 145 g-U/L uranyl nitrate mechanical studies, the sample pump on the AKTA purifier system was used to

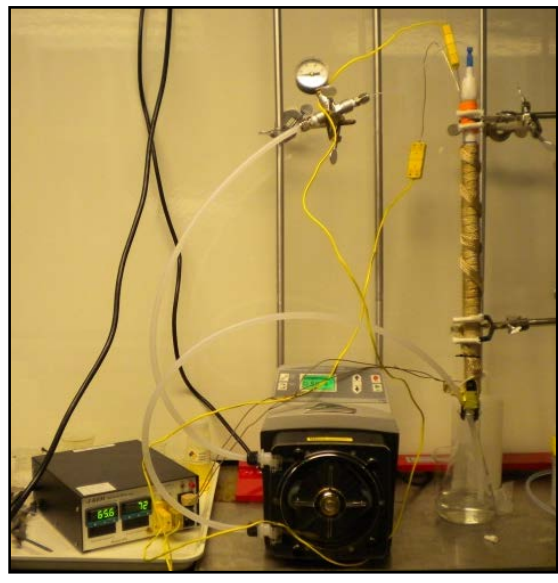

FIGURE C-1 Mechanical Stability Study Setup make the sorbent continuously contact the solution and to record the pressure by using the in-line pressure gauge and Unicorn software. This process was monitored for 8 hours over 3 days; a nitric acid wash followed by a water rinse was done at the end of every day. The background pressure of the system was determined by using a column filled with uranyl nitrate at $60^{\circ} \mathrm{C}$.

\section{C.2 RESULTS}

For the initial studies with water, nitric acid, and ammonium hydroxide, the pressure was recorded at the beginning of the run and at various periods of time throughout the day. At the beginning of the run, the pressure was higher because the temperature of the column had not yet equilibrated. After the temperature had equilibrated within the column, the pressure remained constant for the rest of the day (this is the pressure that was reported). This was the case for S80 and T5M in water, nitric acid, and ammonium hydroxide. The T52 column was stable for the water, and then at the beginning of the nitric acid run, with no significant pressure increase. The pressure dropped after a couple of hours during the nitric acid run; the reported pressure was that after the pressure drop. The pounds per square inch (psi) were converted to atmosphere (atm) to compare the experimental results to the calculated pressure drop from Ergun's equation (Table C-1). 
TABLE C-1 Experimental $\Delta \mathbf{P}$ Compared to Calculated $\Delta P, 60^{\circ} \mathbf{C}^{\mathrm{a}}$

\begin{tabular}{|c|c|c|c|c|c|c|c|c|}
\hline Sorbent & Media & $\begin{array}{l}\text { ID } \\
(\mathrm{cm})\end{array}$ & $\begin{array}{l}\text { Length } \\
(\mathrm{cm})\end{array}$ & $\begin{array}{c}\text { Calculated } \\
\Delta \mathrm{P}(\mathrm{atm})\end{array}$ & $\begin{array}{c}\text { System } \\
\text { Background } \\
(\mathrm{psi})\end{array}$ & $\begin{array}{c}\text { Recorded } \\
\text { Pressure } \\
\text { (psi) }\end{array}$ & $\begin{array}{c}\text { Experimental } \\
\quad \Delta \mathrm{P}(\mathrm{psi})\end{array}$ & $\begin{array}{c}\text { Experimental } \\
\Delta \mathrm{P}(\mathrm{atm})\end{array}$ \\
\hline \multirow[t]{3}{*}{ S80 } & $\mathrm{H}_{2} \mathrm{O}$ & 1.5 & 12 & 0.60 & 9 & 18 & 9 & 0.61 \\
\hline & $0.1 \mathrm{M} \mathrm{HNO}_{3}$ & & & 0.60 & 9 & 17 & 9 & 0.61 \\
\hline & $1 \mathrm{M} \mathrm{NH}_{4} \mathrm{OH}$ & & & 0.60 & 9 & 15 & 8 & 0.54 \\
\hline \multirow[t]{3}{*}{ T52 } & $\mathrm{H}_{2} \mathrm{O}$ & 1.5 & 38 & 0.20 & 5.5 & 9 & 3.5 & 0.24 \\
\hline & $0.1 \mathrm{M} \mathrm{HNO}_{3}$ & & & 0.20 & 5.5 & 6.5 & 1 & 0.07 \\
\hline & $1 \mathrm{M} \mathrm{NH}_{4} \mathrm{OH}$ & & & 0.20 & 5.5 & 6.5 & 1 & 0.07 \\
\hline \multirow[t]{3}{*}{ T5M } & $\mathrm{H}_{2} \mathrm{O}$ & 1.5 & 40 & 0.12 & 5.5 & 6.5 & 1 & 0.07 \\
\hline & $0.1 \mathrm{M} \mathrm{HNO}_{3}$ & & & 0.12 & 5.5 & 6.5 & 1 & 0.07 \\
\hline & $1 \mathrm{M} \mathrm{NH}_{4} \mathrm{OH}$ & & & 0.12 & 5.5 & 7 & 1.5 & 0.1 \\
\hline
\end{tabular}

a All columns were run at a superficial velocity of $21 \mathrm{~cm} / \mathrm{min}(37.1 \mathrm{~mL} / \mathrm{min})$.

The AKTA Purifier 10 system was used to pass the uranyl nitrate solution through the column, and the pressure and temperature were monitored by using the Unicorn software. The data were collected while the temperatures of the columns were equilibrating. The S80 column performed as calculated by using Ergun's equation, with no significant changes in pressure over the 3 days (Table C-2, Figure C-2). The T5M column's experimental $\Delta \mathrm{P}$ was within experimental error, even with the slight pressure drop, due to the range of large particles and significant pulsing within the AKTA sample pump (Table C-2, Figure C-3). The T52 column's $\Delta \mathrm{P}$ was significantly higher at the end of the first day of recording pressure, and it continued to increase over the next 2 days. After a total of 15 hours of uranyl nitrate solution being pumped through the column, the pressure dropped to background, suggesting the formation of channels in the column (Table C-2, Figure C-4). 
TABLE C-2 Experimental $\Delta P$ Versus Calculated $\Delta P$ with a 145 g-U/L Uranyl Nitrate Solution, pH 1 at $60^{\circ} \mathrm{C}$

\begin{tabular}{|c|c|c|c|c|c|c|c|c|}
\hline Sorbent & Day & $\begin{array}{l}\text { ID } \\
(\mathrm{cm})\end{array}$ & $\begin{array}{c}\text { Length } \\
\text { (cm) }\end{array}$ & $\begin{array}{c}\text { Calculated } \\
\Delta \mathrm{P}(\mathrm{atm})\end{array}$ & $\begin{array}{c}\text { System } \\
\text { Backgroun } \\
{\mathrm{d}(\mathrm{psi})^{\mathrm{a}}}^{\mathrm{a}}\end{array}$ & $\begin{array}{c}\text { Recorded } \\
\text { Pressure } \\
(\mathrm{psi})^{\mathrm{a}}\end{array}$ & $\begin{array}{c}\text { Experimental } \\
\Delta \mathrm{P}(\mathrm{psi})^{\mathrm{a}}\end{array}$ & $\begin{array}{c}\text { Experimenta } \\
\Delta \mathrm{P}(\mathrm{atm})\end{array}$ \\
\hline \multirow[t]{3}{*}{ S80 } & 1 & 1.5 & 12 & 0.91 & 134 & 145 & 11 & 0.75 \\
\hline & 2 & & & 0.91 & 134 & 147 & 13 & 0.88 \\
\hline & 3 & & & 0.91 & 134 & 146 & 12 & 0.82 \\
\hline \multirow[t]{3}{*}{ T52 } & 1 & 1.5 & 38 & 0.30 & 134 & 151 & 17 & 1.2 \\
\hline & 2 & & & 0.30 & 134 & 167 & 33 & 2.2 \\
\hline & 3 & & & 0.30 & 134 & $183^{\mathrm{b}}$ & $49^{\mathrm{b}}$ & $3.3^{\mathrm{b}}$ \\
\hline \multirow[t]{3}{*}{ T5M } & 1 & 1.5 & 40 & 0.20 & 134 & 137 & 3 & 0.20 \\
\hline & 2 & & & 0.20 & 134 & 135 & 1 & 0.07 \\
\hline & 3 & & & 0.20 & 134 & 135 & 1 & 0.07 \\
\hline
\end{tabular}

a The pressure was averaged over the run. There was significant pulsing due to the high flow rate and the pump.

b This was the average on Day 3 before the pressure dropped to background.

S80 Mechanical Flow Study, 145g-U/L Uranyl Nitrate

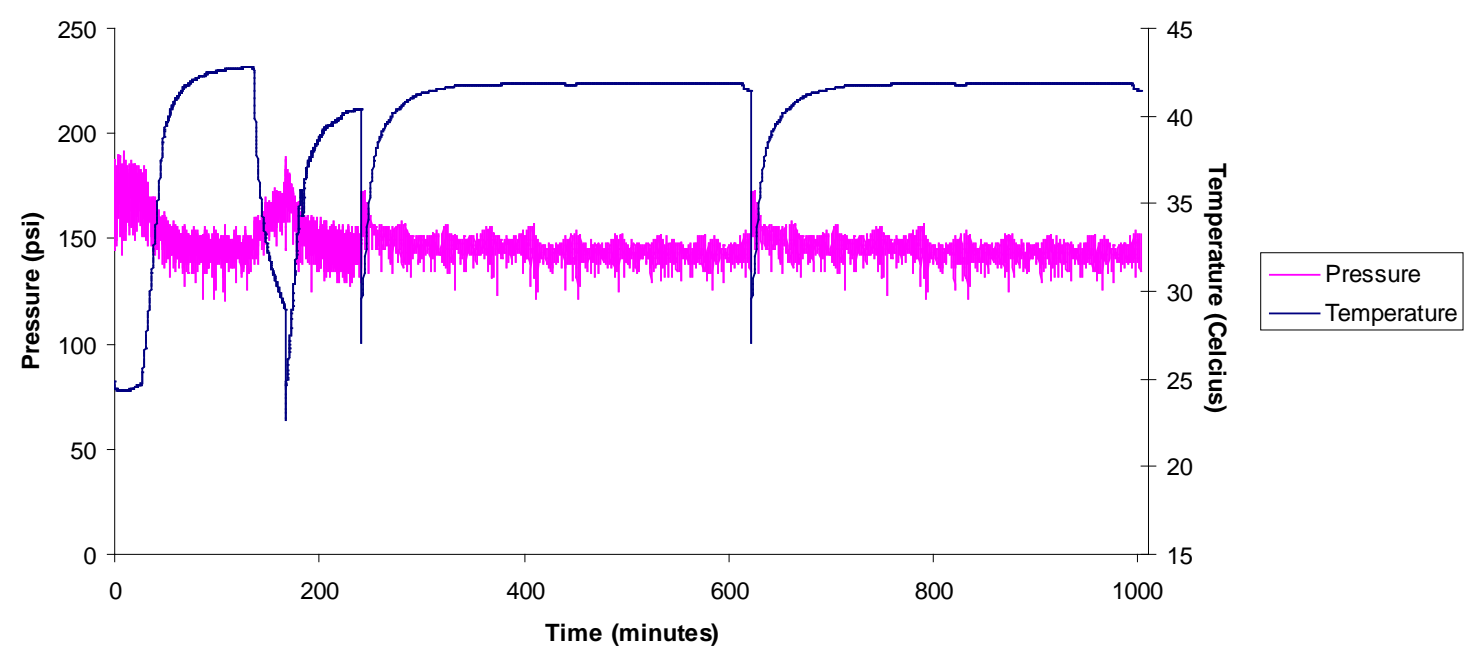

FIGURE C-2 S80 Mechanical Stability Study, 145 g-U/L Uranyl Nitrate Solution [Graph from the mechanical flow studies from the S80 column, with $145 \mathrm{~g}-\mathrm{U} / \mathrm{L}$ uranyl nitrate solution at $\mathrm{pH} 1$ at $60^{\circ} \mathrm{C}$ contacting the sorbent at a flow rate of $37.1 \mathrm{~mL} / \mathrm{min}$. The graph depicts the pressure drop (psi) over the given time frame. The pulsing in the graph is a factor of the flow rate sample pump on the AKTA purifier. The temperature of the solution when it contacts the AKTA temperature probe is also graphed. This also shows the beginning of each day of the run (when the temperature drops to $25^{\circ} \mathrm{C}$; second drop shows issue with the water bath).] 
T5M Mechanical Flow Study, 145g-U/L Uranyl Nitrate

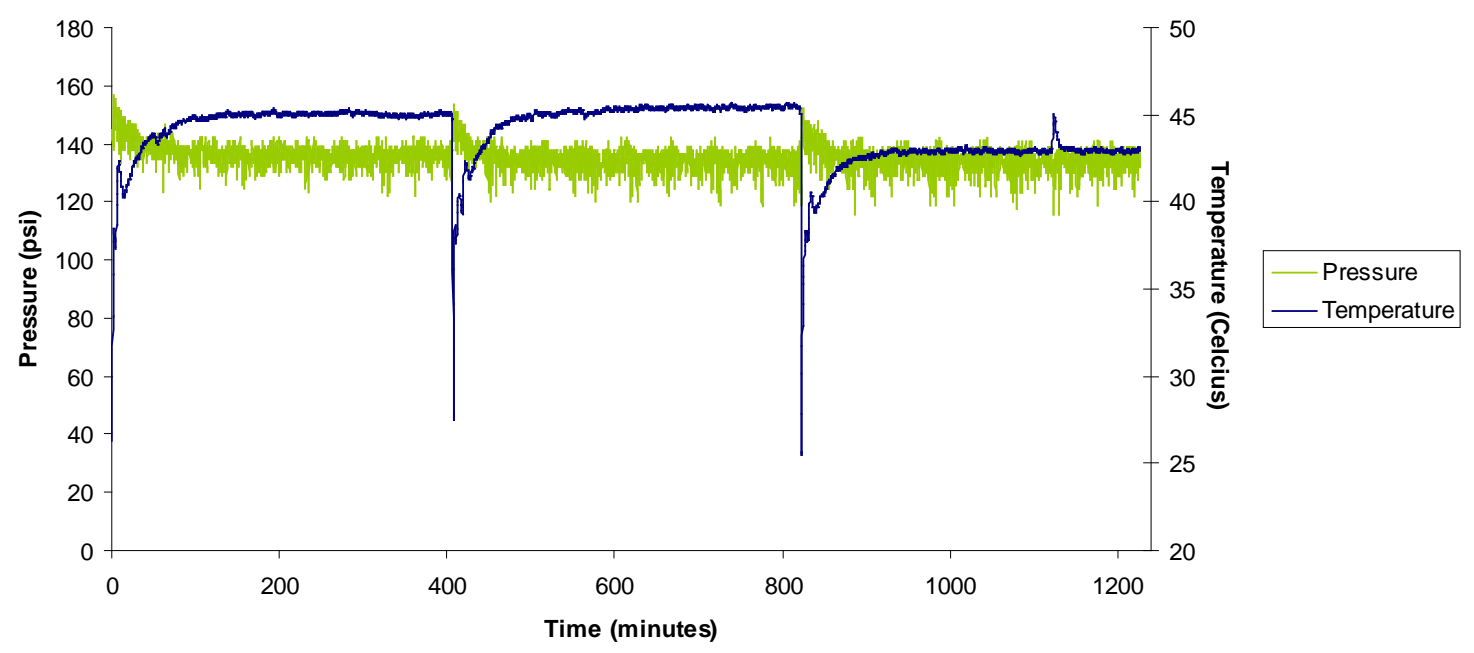

FIGURE C-3 T5M Mechanical Stability Study, 145 g-U/L Uranyl Nitrate Solution [Graph from the mechanical flow studies from the T5M column, with $145 \mathrm{~g}-\mathrm{U} / \mathrm{L}$ uranyl nitrate solution at $\mathrm{pH} 1$ and $60^{\circ} \mathrm{C}$ contacting the sorbent at a flow rate of $37.1 \mathrm{~L} / \mathrm{min}$. The graphs depict the pressure drop (psi) over the given time frame. The pulsing in the graph is a factor of the flow rate sample pump on the AKTA purifier. The temperature of the solution when it contacts the AKTA temperature probe is also graphed. This also shows the beginning of each day of the run (when the temperature drops to $\left.25^{\circ} \mathrm{C}\right)$.] 
T52 Mechanical Flow Study, 145g-U/L Uranyl Nitrate

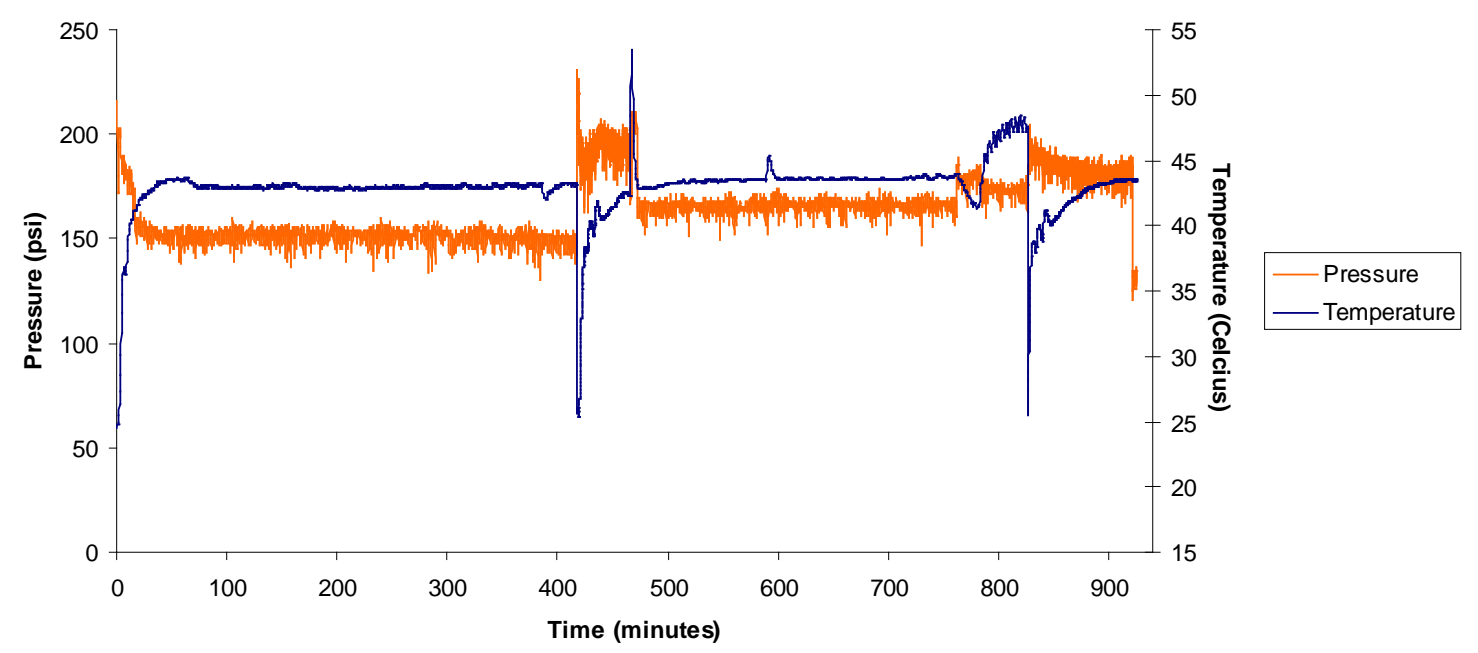

FIGURE C-4 T52 Mechanical Stability Study, 145 g-U/L Uranyl Nitrate Solution [Graph from the mechanical flow study for the T52 column, with $145 \mathrm{~g}-\mathrm{U} / \mathrm{L}$ uranyl nitrate solution at $\mathrm{pH} 1$ and $60^{\circ} \mathrm{C}$ contacting the sorbent at a flow rate of $37.1 \mathrm{~mL} / \mathrm{min}$. The graph depicts the pressure drop (psi) over the given time frame with the pressure drop to background at the end of the run. The pulsing in the graph is a factor of the flow rate and sample pump on the AKTA purifier. The temperature of the solution when it contacts the AKTA temperature probe is also graphed. This also shows the beginning of each day of the run (when the temperature drops to $25^{\circ} \mathrm{C}$ ).] 



\section{Argonne}

Chemical Science and Engineering Division

Argonne National Laboratory

9700 South Cass Avenue, Bldg. 205

Argonne, IL 60439-4837

www.anl.gov 